\title{
Likelihood of aneurysmal subarachnoid haemorrhage in patients with normal unenhanced CT, CSF xanthochromia on spectrophotometry and negative CT angiography
}

\author{
${ }^{1} \mathrm{AK}$ Rana, ${ }^{2} \mathrm{HE}$ Turner, ${ }^{3} \mathrm{KA}$ Deans \\ ${ }^{1}$ Consultant Neuroradiologist, Aberdeen Biomedical Imaging Centre, University of Aberdeen Lilian Sutton Building; ${ }^{2}$ Principal Clinical \\ Scientist, Department of Clinical Biochemistry, Aberdeen Royal Infirmary; ${ }^{3}$ Consultant Chemical Pathologist, Department of Clinical \\ Biochemistry, Aberdeen Royal Infirmary, Foresterhill, Aberdeen, UK
}

\section{ABSTRACT}

Background: Patients with suspected subarachnoid haemorrhage, a normal noncontrast computed tomography (CT) and cerebrospinal fluid (CSF) evidence of haemoglobin breakdown products often undergo CT angiography (CTA). If this is normal, then invasive catheter angiography may be offered. In current clinical practice, haemoglobin breakdown products are detected by spectrophotometry rather than visible xanthochromia, and CTA is performed on multidetector scanners. The aim of this study was to determine if such patients should still have a catheter angiography, given the associated risks.

Methods: Patients positive for CSF spectrophotometry $(n=26)$ were retrospectively identified from the clinical biochemistry information system and imaging data from the electronic radiology records were reviewed. Discharge letters were consulted to relate the biochemistry and radiology results to the final diagnosis.

Results: I5 patients with CT angiography were found. Nine patients had normal CT angiography. No causative aneurysms had been missed. One patient had small, coincidental aneurysms missed on initial reading of the CTA.

Conclusion: The likelihood of a clinically significant aneurysm in a patient who is CT negative, lumbar puncture positive and CTA negative is low. Double reporting of negative CT angiograms may be advisable.

KEYWORDS Angiogram-negative subarachnoid haemorrhage, spectrophotometry, subarachnoid haemorrhage, xanthochromia

DECLARATION OF INTERESTS No conflicts of interest declared.
Correspondence to AK Rana

Aberdeen Biomedical

Imaging Centre,

University of Aberdeen

Lilian Sutton Building,

Foresterhill, Aberdeen

AB25 2ZD, UK

tel. +44 (0)12245 52175

e-mail arnab@imagingsense.com

\section{BACKGROUND}

Subarachnoid haemorrhage (SAH) is a rare, potentially fatal cause of headache. Classically, the patient will present with a sudden onset, severe headache and meningeal signs and/or altered consciousness. One important and treatable cause of SAH is an underlying, contained, ruptured cerebral berry aneurysm. These berry aneurysms require treatment to prevent recurrent $\mathrm{SAH}$, because further bleeds can be more substantial, more disabling, potentially untreatable and fatal. ${ }^{1.2}$

The initial investigation for clinically suspected SAH is unenhanced computed tomography (CT). This has a sensitivity of $91-98 \%$ which decreases with time from onset of symptoms. ${ }^{3,4}$ In many institutions, if SAH is detected on CT, then CT angiography (CTA) is the next line investigation to identify and characterise berry aneurysms with a view to treatment.
Lumbar puncture (LP) is performed in those in whom SAH is suspected clinically but who have normal unenhanced CT results. ${ }^{5}$ Subarachnoid blood is broken down into bilirubin, which produces a visible yellow discolouration of cerebrospinal fluid (CSF) known as xanthochromia. This is measured with high sensitivity using spectrophotometry. ${ }^{6}$ Patients found to have CSF evidence of SAH often undergo CTA with a view to defining size, number and potential treatability of the berry aneurysms.

Not all patients with CSF xanthochromia have aneurysms; ${ }^{7}$ and it is not proven that patients with a positive LP, normal unenhanced CT and normal CTA require further catheter angiographic follow-up. Patients who have been followed up by catheter angiography are sometimes reported as subsets of larger studies. Kershenovich et al. ${ }^{8}$ reported eight patients followed up by catheter angiography. Westerlaan et al. ${ }^{9}$ reported 13 
patients, of whom 12 were followed up with digital subtraction angiography (DSA) and one with repeat CTA. Agid et al. ${ }^{10}$ followed up 32 patients and found one case of vasculitis on DSA, which was retrospectively visible on CTA. Similarly, others reported 16 patients, "1 two patients ${ }^{12}$ and 27 patients. ${ }^{13}$ Thus no aneurysms were identified in a total of 98 patients. No studies were found in which CT and CTA negative but CSF positive patients were the sole subject of investigation.

Catheter angiography is regarded as a gold standard. However, it has a risk of neurological and other complications. A report on 2,899 patients between 1996 and $200 \mathrm{I}^{14}$ noted a $\mathrm{I} .3 \%$ risk of neurological complications and a $0.5 \%$ risk of permanent neurological complications. Fifi et al. ${ }^{15}$ reported no neurological complications in 3,636 patients who had diagnostic angiograms performed only by interventional neuroradiologists in an academic centre. These high-volume centres, performing approximately 500 procedures per year, gain experience which is not achievable in less densely populated areas; and experience is decreasing as noninvasive vascular imaging improves. Clinically undetectable brain ischaemia may be revealed by diffusion-weighted imaging in II-26\% of patients undergoing diagnostic cerebral angiography. ${ }^{16-9}$ Although the clinical significance of such 'silent' ischaemic lesions is debated, there is evidence that the cumulative burden of ischaemic lesions results in neuropsychological deficits or vascular dementia. ${ }^{20}$

The study by Fifi et al. identified one femoral abscess, two femoral occlusions with leg ischaemia requiring surgical revascularisation, one dissecting pseudo-aneurysm requiring thrombin injection and one retroperitoneal haematoma requiring transfusion, ${ }^{15}$ emphasising that non-neurological complications may be serious.

Given the risks of catheter angiography and uncertainty as to whether it is necessary in the sub-group of patients with normal unenhanced CT and CTA, but positive CSF spectrophotometry, we aimed to determine if this group of patients still warrants the risk of catheter angiography in the context of modern CT imaging.

\section{METHODS}

The institutional ethics committee considered that this retrospective study was a clinical audit and therefore did not require ethical approval. However, the departmental data protection officer advised that all patient data should be fully anonymised.

A search of the clinical biochemistry laboratory information system (APEX, iSOFT plc, Banbury, UK) yielded data on all CSF samples positive for haemoglobin breakdown products (analysed using the UvikonXL spectrophotometer, Northstar Scientific, Leeds, UK).
Analysis and reporting were performed in accordance with the UK National External Quality Assessment Service (NEQAS) national guidelines. Net bilirubin absorbance was measured at $476 \mathrm{~nm}$; an absorbance of $\leq 0.007 \mathrm{AU}$ indicated that bilirubin was not raised. Likewise, a net oxyhaemoglobin absorbance of $\leq 0.02 \mathrm{AU}$ indicated that oxyhaemoglobin was not raised. ${ }^{6}$

Patients who had positive spectrophotometry were individually searched on the radiology information system. All images and reports were reviewed, as were the electronic discharge summaries for CTA negative patients. The majority of CT angiograms were performed in Aberdeen Royal Infirmary using a 128-multidetector Siemens Definition (Erlangen, Germany) scanner. A minority of CT angiograms were performed in hospitals with 64-multidetector Toshiba Aquilion (Tokyo, Japan) and on 40-multidetector Philips Brilliance (Best, Netherlands) scanners.

Patients were excluded if there was a known haemorrhage on unenhanced CT or if neurovascular imaging had not been performed. For the purposes of this study, patients with insufficient CSF samples or in whom oxyhaemoglobin levels impaired ability to detect bilirubin were not regarded as LP positive.

\section{RESULTS}

A total of 316 CSF samples were analysed by spectrophotometry between I February 20II and 3I January 2012. There were 26 patients with bilirubin detected by spectrophotometry which was not accounted for by increased serum bilirubin. Figure I shows a breakdown of the samples included in this study.

The excluded patients with known haemorrhage included one post-neurosurgical patient who was being investigated for meningitis, one patient with known contusions who was being investigated for meningitis, one pregnant patient with intracerebral haemorrhages secondary to eclampsia and one patient with a perimesencephalic haemorrhage (the latter patient had CTA performed). One patient with encephalitis and one patient with malignant meningitis secondary to breast cancer had no vascular imaging performed. In five patients the reason for not proceeding to vascular imaging was unclear. Of the remaining 15 patients, six had aneurysms detected by the radiologist on the first $C T$ angiogram. This left nine patients with a negative unenhanced CT, positive CSF spectrophotometry and an apparently normal first CT angiogram. These are presented in Table I. All but two of the patients were imaged in Aberdeen Royal Infirmary.

One 75-year-old patient did have aneurysms missed on CT cerebral angiography which were identified on a 
TABLE I Unenhanced CT negative, LP positive and CTA negative patients. To maintain patient anonymity, patient ages have been altered to the nearest five years where given

\begin{tabular}{|c|c|c|}
\hline Case referral comments & $\begin{array}{l}\text { Lumbar puncture comments } \\
\text { (biochemistry laboratory } \\
\text { comments are in quotation marks) }\end{array}$ & Radiological follow-up/outcome \\
\hline $\begin{array}{l}\text { I History of depression. Patient } \\
\text { intermittently confused. Referrer was } \\
\text { suspecting encephalitis. }\end{array}$ & $\begin{array}{l}\text { 'Bilirubin and oxyhaemoglobin increased. } \\
\text { Consistent with SAH.' }\end{array}$ & $\begin{array}{l}\text { CTA negative. No further vascular } \\
\text { imaging. Discharge diagnosis: } \\
\text { psychogenic headache. Patient alive } 28 \\
\text { months later. }\end{array}$ \\
\hline $\begin{array}{l}2 \text { Known alcoholism, disproportionate } \\
\text { cerebellar atrophy. }\end{array}$ & $\begin{array}{l}\text { 'Bilirubin and oxyhaemoglobin increased. } \\
\text { Consistent with SAH.' }\end{array}$ & $\begin{array}{l}\text { Normal CTA. Discharge diagnosis: } \\
\text { tension type headache. Patient alive } 20 \\
\text { months later. }\end{array}$ \\
\hline $\begin{array}{l}350 \text {-year-old female with three- } \\
\text { day history of gradual onset frontal } \\
\text { headache. Headaches unusual for } \\
\text { this patient and worsening despite } \\
\text { medication. }\end{array}$ & $\begin{array}{l}\text { Eight unsuccessful attempts at LP, } \\
\text { eventually successful under radiological } \\
\text { guidance. Bloodstained CSF. 'Bilirubin } \\
\text { and oxyhaemoglobin increased. } \\
\text { Consistent with SAH.' }\end{array}$ & $\begin{array}{l}\text { One CTA normal. No further imaging } \\
\text { follow-up. History considered not } \\
\text { typical for SAH and the final diagnosis } \\
\text { was prolonged migraine. }\end{array}$ \\
\hline $\begin{array}{l}4 \text { Had presented two days earlier with } \\
\text { sudden onset occipital headache and } \\
\text { nausea. }\end{array}$ & $\begin{array}{l}\text { 'Bilirubin and oxyhaemoglobin increased. } \\
\text { Consistent with SAH. Sample not } \\
\text { protected from light, interpret results } \\
\text { with caution due to possible bilirubin } \\
\text { degradation.' }\end{array}$ & $\begin{array}{l}\text { Patient returned overseas. Discharge } \\
\text { diagnosis: presumed perimesencephalic } \\
\text { haemorrhage. }\end{array}$ \\
\hline $\begin{array}{l}5 \text { 50-year-old male with diabetes, } \\
\text { retinopathy, hypertension and ischaemic } \\
\text { heart disease. Ten days before admission } \\
\text { had thunderclap headache and } \\
\text { vomiting 4-5 hours duration, preceded } \\
\text { by sweating, dizziness and blurred } \\
\text { vision. Dizziness and unsteadiness } \\
\text { on examination. Non-smoker and no } \\
\text { alcohol use. }\end{array}$ & $\begin{array}{l}\text { 'Increased CSF bilirubin. This finding may } \\
\text { be consistent with SAH, an increased } \\
\text { bilirubin accompanying the increased } \\
\text { CSF protein, or other source of CSF } \\
\text { blood.' Persistently raised bilirubin and } \\
\text { protein on LP one month later. No red } \\
\text { cells, white cells organisms or growth } \\
\text { on either occasion. }\end{array}$ & $\begin{array}{l}\text { Normal CT angiogram and normal } \\
\text { catheter angiogram. Symptoms } \\
\text { gradually improved. Later whole spine } \\
\text { MRI showed minor degenerative } \\
\text { changes and high TI signal in a thoracic } \\
\text { intervertebral disc. No final diagnosis } \\
\text { for the headache, speculated post-viral } \\
\text { inflammation. Alive } 28 \text { months later. }\end{array}$ \\
\hline $\begin{array}{l}630 \text {-year-old male with sudden onset } \\
\text { headache nine days before admission. } \\
\text { On citalopram for depression. }\end{array}$ & $\begin{array}{l}\text { Difficult LP successful after multiple } \\
\text { failed attempts. Bruise on back. } \\
\text { 'Increased CSF bilirubin. Consistent with } \\
\text { SAH.' Red cell count } 2 / \mu \mathrm{L} \text {. }\end{array}$ & $\begin{array}{l}\text { CTA normal. Final diagnosis migraine }+ \\
\text { post-LP headache. Alive seven months } \\
\text { later. }\end{array}$ \\
\hline $\begin{array}{l}750 \text {-year-old female with sudden } \\
\text { onset worst headache ever, nausea, } \\
\text { posterior head pain and photophobia. } \\
\text { No neurological signs. }\end{array}$ & $\begin{array}{l}\text { 'Increased CSF bilirubin. Consistent with } \\
\text { SAH. Sample bloodstained - interpret } \\
\text { results with caution.' }\end{array}$ & $\begin{array}{l}\text { CTA and DSA normal. Later diagnosed } \\
\text { as migraine and remains under } \\
\text { neurology follow up. Alive } 28 \text { months } \\
\text { later. }\end{array}$ \\
\hline $\begin{array}{l}875 \text {-year-old female with previous } \\
\text { stroke presenting with bifrontal } \\
\text { headache, nausea and vomiting. }\end{array}$ & $\begin{array}{l}\text { 'Increased CSF bilirubin. Consistent with } \\
\text { SAH.' }\end{array}$ & $\begin{array}{l}\text { Missed aneurysm on initial CTA, } \\
\text { identified on neck CTA eight days later. } \\
\text { Left carotid } 3 \mathrm{~mm} \text { and } 2 \mathrm{~mm} \text { aneurysms } \\
\text { (Figure 2). No additional treatment } \\
\text { or imaging follow-up due to location } \\
\text { of aneurysm possibly being incidental } \\
\text { to her symptoms and patient co- } \\
\text { morbidities.Alive } 22 \text { months later. }\end{array}$ \\
\hline $\begin{array}{l}9 \text { Thunderclap headache and one bout } \\
\text { of vomiting five days before admission. } \\
\text { No neurological signs. }\end{array}$ & $\begin{array}{l}\text { 'Increased CSF bilirubin. Consistent with } \\
\text { SAH.' }\end{array}$ & $\begin{array}{l}\text { CTA, DSA and MRA follow-up negative. } \\
\text { Alive } 18 \text { months later. }\end{array}$ \\
\hline
\end{tabular}

later noninvasive CT angiogram of the neck. These aneurysms were retrospectively visible on the initial CT cerebral angiography (Figure 2). The sac diameters were
$2 \mathrm{~mm}$ and $3 \mathrm{~mm}$, and they were deemed not to be causative after multi-disciplinary review. This patient was also imaged on the 128-multidetector CT scanner. 


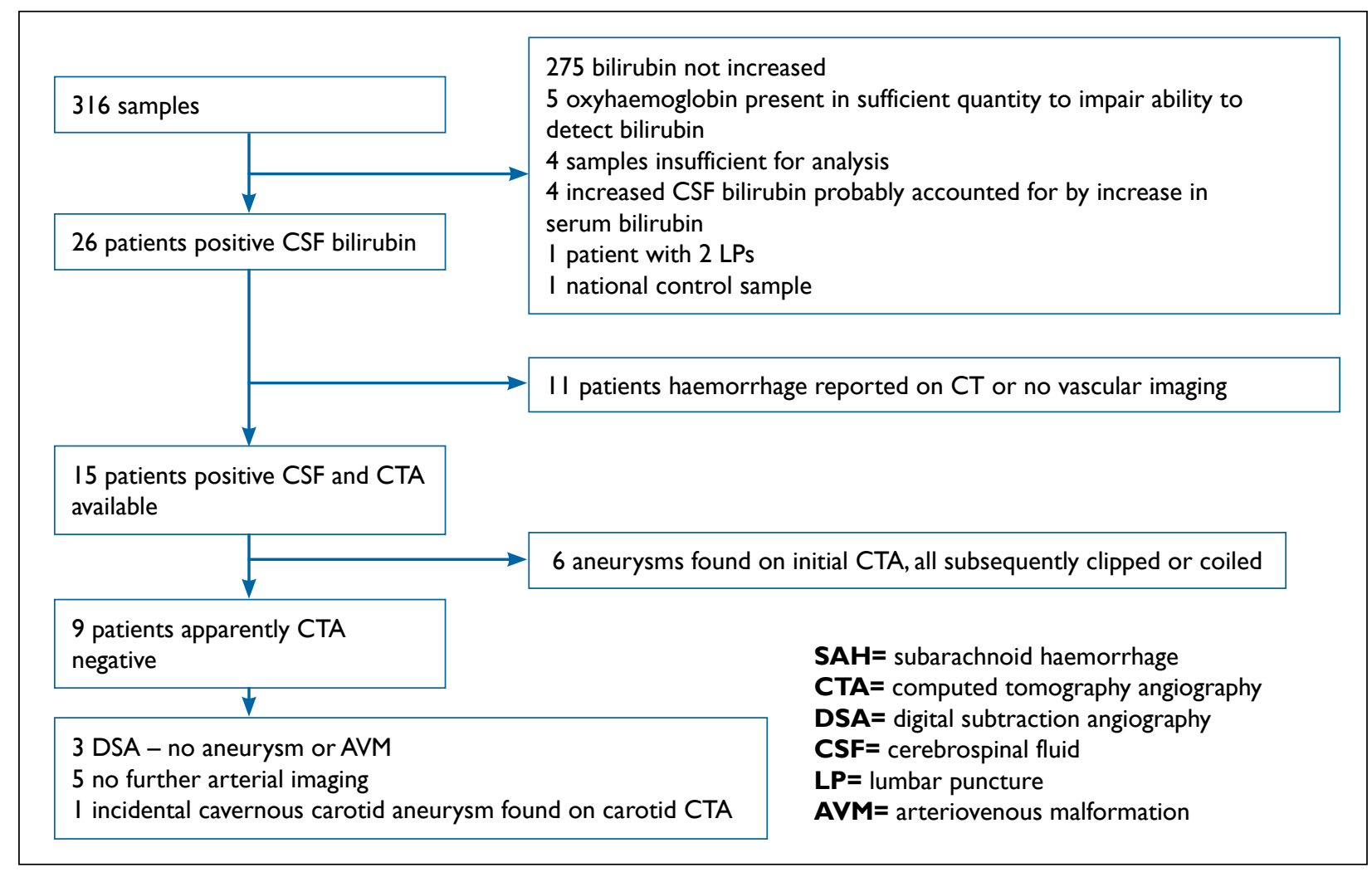

FIGURE I Outline of the retrospective audit.

\section{DISCUSSION}

In our sample of I5 LP positive patients with CT angiography available, six patients had aneurysms detected on the initial CTA and all six subsequently underwent treatment. This gives positive spectrophotometry a positive predictive value (PPV) of $40 \%$ for aneurysms warranting treatment. This compares with PPVs of $72 \%$ for visual inspection (but with poor sensitivity), ${ }^{7,22} 19 \%$ for the Leiden method, ${ }^{23}$ or $3 \%$ for xanthochromic index. ${ }^{24}$

Our cases confirm that positive CSF spectrophotometry occurs in haemorrhagic conditions such as contusions, recent neurosurgery, difficult traumatic LP, perimesencephalic haemorrhage and also in other conditions such as encephalitis and malignant meningitis. In a study using DSA, ${ }^{25}$ the clinical diagnoses in those without aneurysms were traumatic SAH, sickle-cell disease, HIV positive with varicella, migraine and systemic lupus erythematosus plus antiphospholipid syndrome. In a significant proportion of cases the cause of haemoglobin breakdown products was not identified, ${ }^{25}$ however, the outcome was favourable in these patients. ${ }^{26}$ Our patients who had spectrophotometric evidence of xanthochromia and no vascular imaging suggest that CSF biochemistry was performed when not required or that a diagnosis other than SAH was regarded as more likely.

Initial angiography by invasive DSA was not the subject of this study. There are several such studies in patients with no abnormality on CT, and LP-diagnosed haemorrhage. Rinkel et al. ${ }^{28}$ reported three patients who did well on clinical follow-up. Jung et al. ${ }^{29}$ reported 12 patients, all of whom had no significant resultant disability; also, no abnormality was found in the one patient who had a second catheter angiogram. Topcuoglu et al. ${ }^{26}$ did not find the cause of haemorrhage in nine patients. Almandoz et al. $^{30}$ reported five CSF xanthochromia patients who had a negative initial catheter angiogram and no causative aneurysm on follow-up CTA and magnetic resonance angiography (MRA). Our study focused on the use of CTA as the initial vascular imaging. In cases where $\mathrm{SAH}$ is conspicuous on unenhanced CT, it is already known that aneurysms may be missed on CTA if they are small, or if they are multiple aneurysms, ${ }^{31}$ close to bone, ${ }^{11}$ or due to arterial spasm. ${ }^{10}$ Where SAH is not visible on unenhanced CT, this limitation of CTA seemed not to apply. ${ }^{10,11}$

Agid et al. ${ }^{10}$ and Kelliny et al." concluded that CTA without confirmatory catheter angiography (DSA) may be sufficient to exclude ruptured aneurysms for patients without any haemorrhage on plain CT. The strategy of avoiding DSA is gaining acceptance in perimesencephalic $\mathrm{SAH},{ }^{8,10,11}$ and a similar change may occur in CT negative, LP positive and CTA negative patients. The enthusiasm for invasive vascular imaging varies between clinicians, units and countries and is also changing over time as the quality of noninvasive vascular imaging improves. 




FIGURE 2 Missed aneurysms on CT angiography. The internal carotid artery segments are labelled according to the embryonic segments described by Lasjaunias and Santoyo-Vazquez and updated by Gailloud et al. ${ }^{36}$ The ascending cavernous aneurysm measures $2 \times 2 \mathrm{~mm}$ and the clinoid aneurysm measures $5 \times 3 \mathrm{~mm}$.

In one of our patients two very small aneurysms were missed on initial reading by the radiologist on the CT angiogram. These aneurysms, considered to be incidental, were not treated (Figure 2).

Intracavernous aneurysms generally exhibit a benign clinical course. Rupture leads to carotido-cavernous fistulae and rarely, $\mathrm{SAH}^{32,33}$ The ones treated in the van Rooij study had a mean size of $10 \mathrm{~mm}$ if treated by coil embolisation, $21 \mathrm{~mm}$ if treated by occlusion and $27 \mathrm{~mm}$ if treated by bypass. ${ }^{33}$ This compares to $2 \mathrm{~mm}$ in our case.

The paraclinoid location is common in patients with unruptured intracranial aneurysms. However, they represent only 1.4-9.1\% of patients with ruptured aneurysms. ${ }^{27}$ The patients with $\mathrm{SAH}$ treated by Loumiotis et al. had aneurysms with a mean fundus size of $8 \mathrm{~mm}, 79 \%$ of which were less than $10 \mathrm{~mm} .{ }^{27}$ This compares with $3 \mathrm{~mm}$ in our case.

Aneurysms close to bone have a known risk of being missed. Our case resembles the cases published by Kelliny et al." and Agid et al..$^{10}$ Those cases were in the context of CT visible $\mathrm{SAH}$, whereas our case differs in the context of no haemorrhage visible on $\mathrm{CT}$.

Measures to detect aneurysms in apparently negative CTA cases include double reporting of CT angiograms, DSA, repeat $C T$ angiography and follow-up MRA. 
Review of our false-negative CT shows that the aneurysms were visible on the initial CTA. Double-reporting of 'normal' CT angiograms may therefore detect the oversight, a strategy that would require no additional patient attendances. This depends on the second radiologist being attuned to the likely sites of missed aneurysms. Invasive angiography would also have detected these aneurysms. However, as our patient did not require treatment it is inappropriate to recommend DSA, with its attendant risks.

Magnetic resonance angiography is a possible noninvasive follow-up modality. Like DSA, it does not have the difficulty of distinguishing aneurysm from bone, but unlike DSA there is no risk of vascular injury.

Digital subtraction angiography is regarded as the gold standard for excluding vascular pathologies, and avoiding DSA may have disadvantages. DSA may allow vasculitis to be shown as found by Agid et al. ${ }^{10}$ and the sequential images demonstrate abnormal flow through arteriovenous malformations (although a delayed repeat DSA may be required to show a small lesion ${ }^{34}$ ). Another consequence of avoiding DSA is that experience of the procedure may be insufficient to maintain operator competence.

Where does the balance lie between the risk of DSA (and its cost) and that of missing a significant berry aneurysm? The number of patients studied here and elsewhere remains small, limiting any firm conclusions. Others have suggested that, in perimesencephalic haemorrhage, CT angiography alone is the best diagnostic strategy. ${ }^{35}$ However, this is not yet agreed practice in CT normal suspected SAH.

\section{LIMITATIONS OF THIS STUDY}

Our review is limited by the small number of patients found to be CT negative, LP positive and CTA negative, reflecting the rarity of this clinical scenario which has, in turn, led to the small numbers of patient cases published elsewhere. Our study does not consider other potential causes of occult SAH such as vasculitis or reversible cerebral vasoconstriction syndrome. Only three of our nine patients had DSA and this may reflect a change in practice away from DSA. Furthermore, the retrospective nature of this review and clinical review limited to discharge letters meant that the study of clinical information on individual patients was limited. A larger, collaborative, multi-disciplinary, prospective study would benefit our understanding of this type of occult SAH.

\section{CONCLUSION}

The risk of missing a clinically significant aneurysm is low in patients with a normal unenhanced CT, CSF spectrophotometry positive for haemoglobin breakdown products and a negative CTA.

\section{REFERENCES}

I Al-Shahi R, White PM, Davenport RJ et al. Subarachnoid haemorrhage. BMJ 2006; 333:235-40. http://dx.doi.org/10.1/36/ bmj.333.7561.235

2 Greenberg MS. Handbook of neurosurgery. New York: Thieme Publishers; 2010.

3 Carley S, Wallmann P. Towards evidence based emergency medicine: best BETs from the Manchester Royal Infirmary. Does a normal CT scan rule out a subarachnoid haemorrhage? Emerg Med J 200I; I8:27I-3. http://dx.doi.org/I0.I I36/emj.18.4.27I-a

4 Perry IJ, Stiell IG, Sivilotti ML et al. Sensitivity of computed tomography performed within six hours of onset of headache for diagnosis of subarachnoid haemorrhage: prospective cohort study. BMJ 20I I; 343:d4277. http://dx.doi.org/I0.1 I36/bmj.d4277

5 Perry JJ, Spacek A, Forbes $M$ et al. Is the combination of negative computed tomography result and negative lumbar puncture result sufficient to rule out subarachnoid hemorrhage? Ann Emerg Med 2008;51:707-13.http://dx.doi.org/10.1016/j.annemergmed.2007.10.025

6 Cruickshank A, Auld P, Beetham R et al. Revised national guidelines for analysis of cerebrospinal fluid for bilirubin in suspected subarachnoid haemorrhage. Ann Clin Biochem 2008; 45:238-44. http://dx.doi.org/I0.1258/acb.2008.007257

7 Perry JJ, Sivilotti ML, Stiell IG et al. Should spectrophotometry be used to identify xanthochromia in the cerebrospinal fluid of alert patients suspected of having subarachnoid hemorrhage? Stroke 2006; 37:2467-72. http://dx.doi.org/I0.II6I/0I.STR.0000240689 15109.47
8 Kershenovich A, Rappaport ZH, Maimon S. Brain computed tomography angiographic scans as the sole diagnostic examination for excluding aneurysms in patients with perimesencephalic subarachnoid hemorrhage. Neurosurgery 2006; 59:798-80I; discussion 80I-2. http://dx.doi.org/I0.1227/0I.NEU.0000232724 19888.C6

9 Westerlaan HE, Gravendeel J, Fiore D et al. Multislice CT angiography in the selection of patients with ruptured intracranial aneurysms suitable for clipping or coiling. Neuroradiology 2007; 49:997-1007. http://dx.doi.org//0.1007/s00234-007-0293-2

10 Agid R, Andersson T, Almqvist $\mathrm{H}$ et al. Negative CT angiography findings in patients with spontaneous subarachnoid hemorrhage: When is digital subtraction angiography still needed? AJNR Am J Neuroradiol 2010; 31:696-705. http://dx.doi.org/I0.3174/ajnr.AI884

II Kelliny M, Maeder P, Binaghi S et al. Cerebral aneurysm exclusion by $C T$ angiography based on subarachnoid hemorrhage pattern: a retrospective study. BMC Neurol 20II; II:8. http://dx.doi. org/I0.1 I86/I47I-2377-II-8

12 Lin N, Zenonos G, Kim AH et al.Angiogram-negative subarachnoid hemorrhage: relationship between bleeding pattern and clinical outcome. Neurocrit Care 2012; 16:389-98. http://dx.doi.org//0.1007/ s|2028-0I2-9680-6

I 3 Dias AL, Hart J, Lobotesis K et al. Follow-up imaging of spontaneous subarachnoid haemorrhage in patients with negative initial CTA and catheter angiography: a review of 109 cases. Neuroradiology 20I2; 54:SIOO-I. 
14 Willinsky RA, Taylor SM, TerBrugge K et al. Neurologic complications of cerebral angiography: prospective analysis of 2,899 procedures and review of the literature. Radiology 2003; 227:522-8. http://dx.doi.org/10.I I48/radiol.22720I207I

15 Fifi JT, Meyers PM, Lavine SD et al. Complications of modern diagnostic cerebral angiography in an academic medical center. $J$ Vasc Interv Radiol 2009; 20:442-7. http://dx.doi.org/10.1016/j. jvir.2009.01.012

I6 Krings T, Willmes K, Becker $\mathrm{R}$ et al. Silent microemboli related to diagnostic cerebral angiography: a matter of operator's experience and patient's disease. Neuroradiology 2006; 48:387-93. http://dx.doi. org/I0.1007/s00234-006-0074-3

17 Bendszus M, Koltzenburg M, Burger R et al. Silent embolism in diagnostic cerebral angiography and neurointerventional procedures: a prospective study. Lancet 1999; 354:1594-7. http://dx.doi.org/I0.1016/ S0I40-6736(99)07083-X

I8 Chuah KC, Stuckey SL, Berman IG. Silent embolism in diagnostic cerebral angiography: detection with diffusion-weighted imaging. Australas Radiol 2004; 48:I33-8. http://dx.doi.org/l0.IIII/j 1440-1673.2004.01273.x

19 Kato K, Tomura N, Takahashi S et al. Ischemic lesions related to cerebral angiography: evaluation by diffusion weighted $M R$ imaging. Neuroradiology 2003; 45:39-43.

20 Bendszus $M$, Stoll $G$. Silent cerebral ischaemia: hidden fingerprints of invasive medical procedures. Lancet Neurol 2006; 5:364-72. http://dx.doi.org/I0.1016/SI474-4422(06)704/2-4

2I Graves P, Sidman R. Xanthochromia is not pathognomonic for subarachnoid hemorrhage. Acad Emerg Med 2004; I I: | 3 |-5.

22 Dupont SA,Wijdicks EFM, Manno EM et al.Thunderclap headache and normal computed tomographic results: value of cerebrospinal fluid analysis. Mayo Clin Proc 2008; 83:1326-3I. http://dx.doi. org/10.4065/83.12.1326

23 Alons IME,Verheul RJ, Ponjee GAE et al. Optimizing blood pigment analysis in cerebrospinal fluid for the diagnosis of subarachnoid haemorrhage - a practical approach. Eur J Neurol 2013; 20:193-7. http://dx.doi.org/ I0. I I I I/j.| I468-I33I.20I2.03834.x

24 Wood MJ, Dimeski G, Nowitzke AM. CSF spectrophotometry in the diagnosis and exclusion of spontaneous subarachnoid haemorrhage. J Clin Neurosci 2005; 12:|42-6. http://dx.doi. org/10.1016/j.jocn.2004.05.009

25 Heasley DC, Mohamed MA, Yousem DM. Clearing of red blood cells in lumbar puncture does not rule out ruptured aneurysm in patients with suspected subarachnoid hemorrhage but negative head CT findings. AJNR Am J Neuroradiol 2005; 26:820-4.
26 Topcuoglu MA, Ogilvy CS, Carter BS et al. Subarachnoid hemorrhage without evident cause on initial angiography studies: diagnostic yield of subsequent angiography and other neuroimaging tests. J Neurosurg 2003; 98:1235-40. http://dx.doi.org//0.3I7I// ins.2003.98.6.1235

27 Loumiotis I, D'Urso PI, Tawk R et al. Endovascular treatment of ruptured paraclinoid aneurysms: results, complications, and followup.AJNRAm J Neuroradiol 20 12;33:632-7. http://dx.doi.org/I0.3 I74/ ajnr.A2825

28 Rinkel GJ, van Gijn J, Wijdicks EF. Subarachnoid hemorrhage without detectable aneurysm. A review of the causes. Stroke 1993; 24: |403-9. http://dx.doi.org/ I0. I I6 I/0I.STR.24.9.1403

29 Jung JY, Kim YB, Lee JW et al. Spontaneous subarachnoid haemorrhage with negative initial angiography: a review of 143 cases. J Clin Neurosci 2006; I3:I0I I-7. http://dx.doi.org/I0.1016/j. jocn.2005.09.007

30 Delgado Almandoz JE, Jagadeesan BD, Refai D et al. Diagnostic yield of computed tomography angiography and magnetic resonance angiography in patients with catheter angiography-negative subarachnoid hemorrhage. J Neurosurg 2012; 117:309-15. http:// dx.doi.org/ I0.3 I7 I/20I2.4.JNSI I 2306

3I Anderson GB, Steinke DE, Petruk KC et al. Computed tomographic angiography versus digital subtraction angiography for the diagnosis and early treatment of ruptured intracranial aneurysms. Neurosurgery 1999; 45:1315-20; discussion 1320-2. http://dx.doi. org/10.1097/00006/23-1999/2000-00008

32 van der Schaaf IC, Brilstra EH, Buskens E et al. Endovascular treatment of aneurysms in the cavernous sinus: a systematic review on balloon occlusion of the parent vessel and embolization with coils.Stroke 2002;33:3 I3-8.http://dx.doi.org//0.1 I6I/hs0 I02.101479

33 van Rooij WJ. Endovascular treatment of cavernous sinus aneurysms. AJNR Am J Neuroradiol 2012; 33:323-6. http://dx.doi. org/l 0.3I74/ajnr.A2759

34 Delgado Almandoz JE, Jagadeesan BD, Refai D et al. Diagnostic yield of repeat catheter angiography in patients with catheter and computed tomography angiography negative subarachnoid hemorrhage. Neurosurgery 2012; 70:1135-42. http://dx.doi.org/10.1227/ NEU.0b0I3e318242575e

35 Ruigrok YM, Rinkel GJ, Buskens E et al. Perimesencephalic hemorrhage and CT angiography: a decision analysis. Stroke 2000; 3 I:2976-983. http://dx.doi.org/I0.I I6I/0I.STR.3 I.I2.2976

36 Gailloud P, Clatterbuck RE, Fasel JHD et al. Segmental agenesis of the internal carotid artery distal to the posterior communicating artery leading to the definition of a new embryologic segment. AJNR Am J Neuroradiol 2004; 25: I I89-93. 